\title{
The influence of the infrastructure characteristics in urban road accidents occurrence
}

\author{
Sandra Vieira Gomes* \\ National Laboratory of Civil Engineering, Transportation Department, Portugal
}

\section{A R T I C L E I N F O}

\section{Article history:}

Received 10 October 2012

Received in revised form 26 February 2013

Accepted 28 February 2013

\section{Keywords:}

GIS

Accident prediction models

Generalized linear modelling

Road accidents

Urban intersections

Urban segments

\begin{abstract}
A B S T R A C T
This paper summarizes the result of a study regarding the creation of tools that can be used in intervention methods in the planning and management of urban road networks in Portugal.

The first tool relates the creation of a geocoded database of road accidents occurred in Lisbon between 2004 and 2007, which allowed the definition of digital maps, with the possibility of a wide range of consultations and crossing of information.

The second tool concerns the development of models to estimate the frequency of accidents on urban networks, according to different desegregations: road element (intersections and segments); type of accident (accidents with and without pedestrians); and inclusion of explanatory variables related to the road environment. Several methods were used to assess the goodness of fit of the developed models, allowing more robust conclusions.

This work aims to contribute to the scientific knowledge of accidents phenomenon in Portugal, with detailed and accurate information on the factors affecting its occurrence. This allows to explicitly include safety aspects in planning and road management tasks.
\end{abstract}

(c) 2013 Elsevier Ltd. All rights reserved.

\section{Introduction}

According to official statistics, a large percentage of accidents are reported in Portuguese urban areas. For instance, from 2004 to 2010 , about $70 \%$ of all injury accidents and $45 \%$ of the fatalities occurred inside urban agglomerations (ANSR, 2010). This significant problem was also identified in the city of Lisbon, which was the case study for the development of a PhD Thesis. The main purpose of the research was to develop methods for managing the safety of urban road networks, particularly those applied to Lisbon. The methods focused on the construction of a geocoded accident database and on the estimation of the expected accident frequencies that allow the identification of hazardous sites.

This paper describes the steps that were taken to build these two tools. The geocoded accident database included injury and Property Damage Only accidents (PDO) occurred in Lisbon from 2004 to 2007. A sketch was associated to each accident, allowing identifying the manoeuvres involved. In what concerns the accident predictive models (APMs), the Negative Binomial modelling framework was used. Sixteen types of models were foreseen: flow-only and models with covariates applied to accidents with pedestrians and other injury accidents occurred at intersections (three legs, four legs and roundabouts) and in segments.

\footnotetext{
* Tel.: +351 218443528; fax: +351 218443029

E-mail address: sandravieira@lnec.pt
}

The paper is organized as follows: the first section provides a brief background about existing statistical models developed in Portugal and elsewhere in Europe, the second section describes the methodology used for the construction of the accident database in the GIS; the third section presents the characteristics of the data used in this study; the fourth section focuses on the estimation of the APMs; the fifth section summarizes the modelling results; and the last section provides a summary of the study and of the advantages of the use of these APM in intervention methods in the planning and management of road networks.

\section{Background on APM}

The development of accident prediction models is not new in the road safety research. Several authors, all around the word have published their work in this scope. Different types of models have been developed, according to level of disaggregation of the variables used: aggregated and disaggregated models.

Aggregate models allow the description of general safety trends on the regional or national level, making possible the development of short-term safety estimations, as a function of traffic and macro-economic variables. For instance, Washington et al. (2006) developed accident prediction models for several accident desegregations using a log linear regression model with variables regarding: population, road length, vehicles kilometres travelled, intersections density, average income and number of housing units. 